\title{
Are the Estimates of Catastrophic Health Expenditure Among Rural Population too High? A Comparison of Studies in Vietnam
}

\author{
Nguyen Thi Bich Thuan ${ }^{*}, 1,2$, Curt Lofgren ${ }^{2}$, Nguyen Thi Kim Chuc ${ }^{3}$ and Lars Lindholm ${ }^{2}$ \\ ${ }^{1}$ Planning and Financing Department, Ministry of Health, Hanoi, Vietnam \\ ${ }^{2}$ Umeå International School of Public Health, Umeå University, Umeå, Sweden \\ ${ }^{3}$ Public Health Faculty, Hanoi Medical University, Hanoi, Vietnam
}

\begin{abstract}
Objective: To describe the proportion of the households that experienced catastrophic health expenditure and to compare the magnitude of catastrophic health expenditure that is estimated from three different data sets in Vietnam.

Methods: The study we are comparing with is based on data from the Vietnam Living Standard Survey (VLSS) 1997/98. We have used data from the 2001 re-survey. The FilaBavi sample consists of 11,089 households. We have also conducted a special survey from July 2001 to June 2002. The sample is smaller, 629 households, but they have been followed for an entire year with monthly interviews. For VLSS and FilaBavi, re-census survey households were interviewed once with a recall period of one month.

Findings: In the VLSS data and in the FilaBavi re-census survey it was found that $9 \%-10 \%$ of the households experienced catastrophic healthcare spending. But, only 5\% (average per month) and $1 \%$ (for the whole year) of the households in the special survey report catastrophic spending.

Conclusions: We suggest that the major reason for the difference in the estimates is the different data collection methods. When doing a cross sectional study with a relatively short recall period there is a risk that households will tend to overestimate non-recurrent large expenditures as that for health.
\end{abstract}

Keywords: Out-of-pocket payment, catastrophic health expenditure, households, Vietnam.

\section{INTRODUCTION}

Any health expenditure that threatens a household's financial capacity to maintain its subsistence needs is termed as catastrophic and does not necessarily equate to high healthcare costs. Even relatively small expenditures on health can be financially disastrous for poor households [1].

In many developing countries, out-of-pocket payments for healthcare are a substantial share of total healthcare costs. Health insurance is, at the same time, often lacking. In this situation, illness and injuries may be a catastrophe for a household also in an economic sense. Hence the term catastrophic is used for any expenditure that risks impoverishing a household [2-5].

Since 1986, the Vietnamese Government has been implementing an initiative of reform, called "Doimoi" aimed at increasing economic growth. During the "Doimoi" period, policy has changed from central planning to a marketoriented economy and the Vietnamese economy continues to grow rapidly, with living standards of both urban and rural populations improving significantly. Coupled with this growth, however, has been a rapid widening of the economic gap between the rich and poor [6]. Vietnam is still a poor

*Address correspondence to this author at the Planning and Financing Department, Ministry of Health, Hanoi, Vietnam; E-mail: ntbthuan2007@gmail.com country. While the annual income per capita has increased by $5-6 \%$, the average annual income remained around USD370 in 2002 [7, 8]. In 2002, the national budget allocated for healthcare was still limited to approximately USD5.7 (VND91,100) per capita per year [9]. Therefore, the government has implemented a number of measures to mobilize new resources for the heath sector. Among the most important measures have been the introduction of user fees at public hospitals, health insurance schemes, and the legalization of the pharmaceutical industry and the retail trade in drugs $[6,10,11]$. These changes have led to significant improvements in the quality of Vietnam's healthcare $[12,13]$. However, they have also lead to an increase in out-of-pocket health expenditures as a proportion of total health expenditures, from 59\% in 1989 to 84\% 1998 and $80 \%$ in 2001. It is also reasonable, therefore, to expect a high ratio for catastrophic health spending.

A number of studies have made estimates of the size of catastrophic health expenditure. In one such study [2] it was found that for $10.5 \%$ of Vietnamese households, spending on healthcare in relation to income was so large that it could be labeled catastrophic. However, there are also reasons to question estimates of catastrophic spending of this magnitude. If one out of ten households in a country each year would be subject to catastrophic health spending it would, within only a few years, mean that the majority of 
households would find themselves in this situation, risking impoverishment.

In this paper, we report on a study from Vietnam using two data sets from a demographic surveillance site. One data set is unique in the sense that the household data have been collected monthly for an entire year. From those data, we analyzed the economic burden on households that healthcare expenditure represents.

The aim of the paper is to compare the magnitude of catastrophic health expenditure that is estimated from three different data sets in Vietnam. More specifically, we aim to describe the proportion of households that experienced catastrophic health expenditure, i.e. health expenditure that is so large in relation to household income that households risk impoverishment as an effect of their healthcare consumption. We also investigate the different data collection methods to explore possible causes of different results from different data sets.

\section{METHODS}

\section{Study Design and Setting}

In this study, three estimates of catastrophic health expenditure are compared. One estimate, which was made by $\mathrm{Xu}$ et al. [2], is done on data from the Vietnam Living Standards Survey 1997 [14]. The other two estimates are done on data from a demographic surveillance site in the Bavi district of Vietnam: The Epidemiological Field Laboratory for Health Systems Research (FilaBavi). This site was established in 1996, as collaboration between Vietnamese and Swedish public health scientists. FilaBavi aims to implement a longitudinal epidemiological surveillance system to generate basic health and healthcare data, supply information for health planning, serve as a background and sampling frame for specific studies and constitute an epidemiological training setting for research students. In 1999, a baseline household survey was undertaken, followed by quarterly surveillance of vital events and complete re-surveys every two years [15].

The Bavi district lies within Hatay province and is a rural community located west of Hanoi in northern Vietnam. The district has a population of approximately 240,000 spread over 410 square $\mathrm{km}$, including lowland, highland and mountainous areas. The Bavi district was selected as a location that is typical of northern Vietnam with respect to geography, socio-economy and health status. Bavi has one district health centre, 3 polyclinics and 32 commune health stations (CHS), one in each commune.

In FilaBavi, a sample of 67 local clusters was made, with probability proportional to size, amounting to 51,024 persons in 11,089 households. An infrastructure with trained interviewers has been built up. These interviewers visit the households every third month. The quarterly surveys gather data on vital health events. The resurveys every second year also include data on household total expenditure and expenditure specifically for healthcare and food. We have used data from the 2001 re-survey for our study [15].

From July 2001 to June 2002, we conducted a special survey focusing on the economic burden that healthcare places on households. A smaller sample was selected for this special survey. Assuming $\alpha$ level of $5 \%$ and a $50 \%$ probability that a household will have an episode of illness in a year, the required sample size becomes 576. To ensure adequate sample size, one out of every 18 households was randomly selected from the larger FilaBavi sample for the purpose of this study. The procedure generated a sample of 629 households.

For this special study, the interviewers visited the households every month during this one-year period with the objective to capture more accurately, what had happened since the last interview. The households provided information on the household's health situation, healthcare utilization, health and food expenditures and total expenditures. Households kept daily notes of their health situation, healthcare payments, total expenditure and income. During the first week of each month, the interviewer conducted an interview based on a part of the daily notes from the previous month. The interviews were carried out by 42 qualified interviewers employed by the larger FilaBavi project. All interviewers had completed high school and were inhabitants of the Bavi district. The interviewers used a structured questionnaire and were given special training on data collection strategies for collecting information on expenditure and illnesses. Ten per cent of the questionnaires were randomly selected for re-interviews before data entry.

Microsoft ACCESS was used for data entry and data analyses were performed using SPSS and STATA software.

\section{Definitions and Measurements Used}

Out-of-pocket health payments are those made by households at the point of receiving health services and includes cash and in-kind payments reported in the surveys [5].

Catastrophic health expenditure is defined in relation to a household's capacity to pay. Health spending is taken to be catastrophic when the ratio to total spending exceeds a certain level. However, there is no consensus on where this threshold should lie. In different studies, health expenditure has been labeled catastrophic if a household's financial contributions to the health system exceed $10 \%, 20 \%, 30 \%$ or $40 \%$ of household resources or ability to pay [2, 16-18].

Based on the aims of this paper, we describe the ratio of households experiencing catastrophic healthcare expenditure according to the thresholds of expenditures greater than $10 \%, 20 \%, 30 \%$, and $40 \%$ of their capability to pay. To compare the magnitude of catastrophic health expenditure between three data sets, we used the methodology developed by $\mathrm{Xu}$ et al. [2, 7, 19, 20]. With this approach, catastrophic spending occurs when healthcare expenditure for a household exceeds $40 \%$ of the households' capacity to pay. This threshold was also suggested for use in developing countries by the World Health Organization.

A household's capacity to pay (CTPi) is calculated in the following way:

$$
\begin{gathered}
C T P_{i}=T E X P_{i}-S E_{(45-55) i} \text { If } F E X P_{i} \succ S E_{(45-55) i} \\
C T P_{i}=T E X P_{i}-F E X P_{i} \text { If } F E X P_{i} \prec S E_{(45-55) i}
\end{gathered}
$$

TEXP denotes total expenditure and FEXP denotes food expenditure. $S E$ stands for subsistence expenditure and is the 
average food expenditure for households whose food expenditure share of total expenditure is in the $45^{\text {th }}$ to $55^{\text {th }}$ percentile. Household expenditure has been adjusted for the number of household members in the following way (also according to $\mathrm{Xu}$ et al. [2]:

\section{$\frac{\text { household expenditure }}{\text { household size }}$}

If $\beta=1$, a household with four members would have to have four times the expenditure of a single member household to be on the same expenditure (consumption) level. If $\beta=0$ no adjustment is made for household size. We have chosen $\beta=0.56$, which is the coefficient used by $\mathrm{Xu} e t$ $a l$. to which we are comparing our results. The value of the parameter $\beta$ (0.56) has been estimated from previous studies based on household survey data from 59 countries $[18,21]$.

The logic behind this approach is that health expenditure is compared to actual non-food expenditure for poorer households while for richer households - that may be expected to spend more on food than what represents necessities - health expenditure is compared to nonsubsistence expenditure.

Socio-economic status (SES) is classified by household total expenditure quintiles. Expenditure, rather than income, is commonly used as a measure of SES in developing countries for three reasons. First, expenditure more accurately reflects the basic purchasing power of the household. Second, households may be less willing to state their true income or may underestimate their total income. Third, expenditure may vary less over time than income, therefore it is easier to measure $[2,22]$.

$\mathrm{Xu}$ et al. [2] use data from the Vietnam Living Standard Survey (VLSS) 1997-98 [14]. In that survey and in the FilaBavi re-survey in 2001, household food expenditure is adjusted for the consumption of food from self-production. This was not originally done in our special survey 2001/02. We have therefore adjusted our data on food expenditure in the following way:

$$
\text { Food expenditure in our study } * \frac{1}{1-Y}
$$

Where $Y=$ the share of food from self-production or nonpurchase out of total food consumption. $Y$ is given in VLSS for the different expenditure quintiles (see Table 1).

Table 1. The Share of Food from Own Production or Non Purchase Out of Total Food Consumption by Per Capita Expenditure Quintile 1998 (VLSS) for Rural Areas

\begin{tabular}{|c|c|c|c|c|c|}
\hline \multicolumn{5}{|c|}{ Expenditure Quintile } & \multirow{2}{*}{ All } \\
\hline $\mathbf{1}$ & $\mathbf{2}$ & $\mathbf{3}$ & $\mathbf{4}$ & $\mathbf{5}$ & \\
\hline \hline 52.29 & 44.16 & 38.05 & 31.96 & 20.39 & 36.37 \\
\hline
\end{tabular}

Source: Vietnam Living Standards Survey 1997-98.

To validate the results we have also studied the proportion of households below different poverty lines and household total expenditure in the different expenditure quintiles for the three data sets we are comparing.
Poverty or the poverty line can be defined in many ways. It includes low income, poor access to resources and skills, vulnerability, insecurity and disempowerment. However, one fundamental dimension of poverty is, unarguably, low income. The poverty line is an expenditure level that allows households to provide themselves with a minimum of goods and services usually defined in terms of basic nutritional needs [23].

In cooperation with the General Statistical Office in Hanoi and the World Bank, two poverty lines were estimated on the VLSS 97-98 data. In 1998 prices, the food poverty line per person/year is $1,286,833$ VND. The overall poverty line is $1,789,871 \mathrm{VND}$ per person/year in 1998 prices, and allows for a minimum consumption above the food poverty line [24].

We have used the GDP deflator to bring the poverty lines to 2002 prices, which for the food poverty line gives $1544200 \mathrm{VND}$ per person/year and for the overall poverty line 2147845 VND per person/year.

\section{Ethical Considerations}

This study was approved by the Scientific and Ethical Committee, Hanoi Medical University, and the Ministry of Health (Decision -QD-BYT-2001). The study was also agreed to by the local authorities, and heads of households.

\section{RESULTS}

The FilaBavi 2001 re-census survey was answered by 10,220 out of 11,089 households. There was an average of 4.25 persons per household. The monthly repeated interviews were completed for 621 (with 2727 persons) of the 629 households selected for the study. Data were missing for 8 of the 629 households. Six households moved from Bavi and 2 households dropped out after three months because they did not wish to continue participation in the survey. The average persons per household are 4.4.

Household total expenditure in the three data sets is of roughly the same size both for the mean and within the different expenditure quintiles (Table 2). These parameters were used as a basis for considering whether the different data sets are vastly different populations in this respect, which would limit our conclusions on catastrophic expenditure.

The extent of poverty within the data sets also appears similar (Table 3). Vietnam has, during the period covered in Table 3, experienced rapid economic growth, which has lifted many households out of poverty. The share of households below the poverty line in the special survey 2001/02 therefore corresponds well to earlier VLSS data.

There is a large difference in the percentage of households experiencing catastrophic health expenditure between the special survey 2001/02 and the two other data sets (Fig. 1). In the special survey with monthly follow-ups during the entire year, only $1 \%$ of the households have health care costs in excess of $40 \%$ of capacity to pay. However, the corresponding share is approximately $5 \%$ on average in each separate month in the special survey. In the two other data sets, which are cross sectional with a recall 
Table 2. Household Total Expenditures Per Year and Household Member in Vietnamese Dong, Constant Prices** (Reference Year 2002)

\begin{tabular}{|c|c|c|c|c|}
\hline \multirow{3}{*}{ Average within Quintiles } & \multicolumn{4}{|c|}{ Total Expenditure } \\
\hline & \multicolumn{2}{|c|}{ VLSS* 97/98 } & \multicolumn{2}{|c|}{ Bavi District } \\
\hline & All of Vietnam & Rural Districts & $\begin{array}{c}\text { Filabavi Re-Census } \\
2001\end{array}$ & $\begin{array}{c}\text { Special Survey } \\
01 / 02\end{array}$ \\
\hline First & 1411684 & & 806788 & 1058654 \\
\hline Second & 2080187 & & 1432706 & 1664007 \\
\hline Third & 2690872 & & 2000292 & 2308426 \\
\hline Fourth & 3687001 & & 2902957 & 3349140 \\
\hline Fifth & 7317390 & & 11076196 & 7262511 \\
\hline Mean & 3429236 & 2729417 & 3641237 & 3127227 \\
\hline Median & & & 1952830 & 2276650 \\
\hline
\end{tabular}

*Vietnam Living Standards Survey 1997-1998.

**Data from VLSS 97/98, which are in constant prices for January 1998, have been expressed in 2002 prices using the GDP deflators for 1998-2002 (with half of the inflation rate for 1998). Expenditure data from Filabavi re-census refers to one month in the second quarter of 2001 (multiplied to yearly sums). The special survey refers to the one year period from July 2001 to June 2002. For these data half of the inflation rate for 2002, as expressed by the GDP deflator, has been used to calculate constant prices.

Table 3. The Share of Households Below the Food Poverty Line and the Overall Poverty Line in the Vietnam Living Standard Surveys (VLSS) and the Bavi Study. Gini Coefficients

\begin{tabular}{|c|c|c|c|c|c|}
\hline & \multicolumn{2}{|c|}{ VLSS 92-93 } & \multicolumn{2}{c|}{ VLSS 97-98 } & Special Survey 01-02 \\
\hline & All of Vietnam & Rural Districts & All of Vietnam & Rural Districts & $18 \%$ \\
\hline \hline Food poverty line & $25 \%$ & $29 \%$ & $15 \%$ & $45 \%$ & $35 \%$ \\
\hline Overall poverty line & $58 \%$ & $66 \%$ & $37 \%$ & & \\
\hline Gini coefficients* & & & & 0.28 & \\
\hline Expenditure per capita & 0.33 & 0.28 & 0.35 & \\
\hline
\end{tabular}

*The Gini coefficient measures income (expenditure) distribution. It takes values between 0 and 1, where 0 means a perfectly equal distribution (everybody has the same expenditure) and 1 means a perfectly unequal distribution (one household accounts for all the expenditure).

Source: Vietnam Living Standards Survey 1997-98.

period of one month, the corresponding share of households is $9-10 \%$.

Fig. 2 shows the proportion of households corresponding to different ratios of health expenditures to the household's capacity to pay. The household expenditures were adjusted for self-produced food. The ratios of households with healthcare expenditures greater than $10 \%$, $20 \%, 30 \%$ and $40 \%$ of their payment capability were approximately $13 \% ; 3 \% ; 2 \%$ and $1 \%$, respectively.

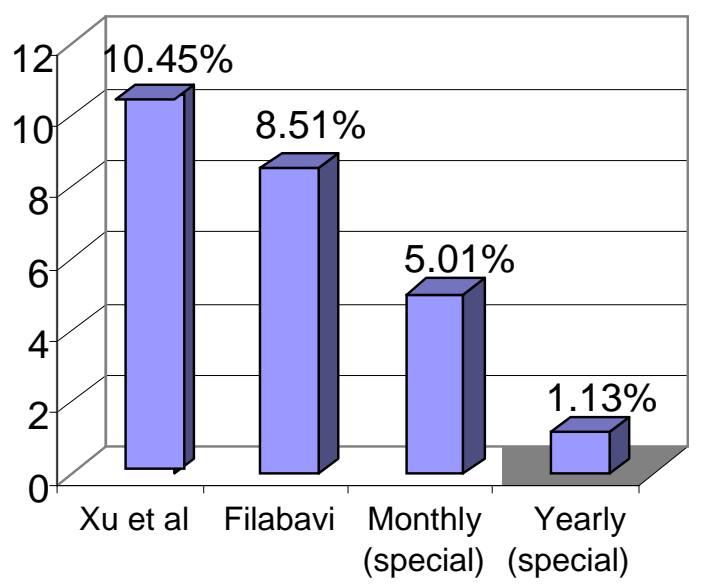

$\square \times 40 \%$

Fig. (1). Comparision of household catastrophic expenditure for three data sets. 


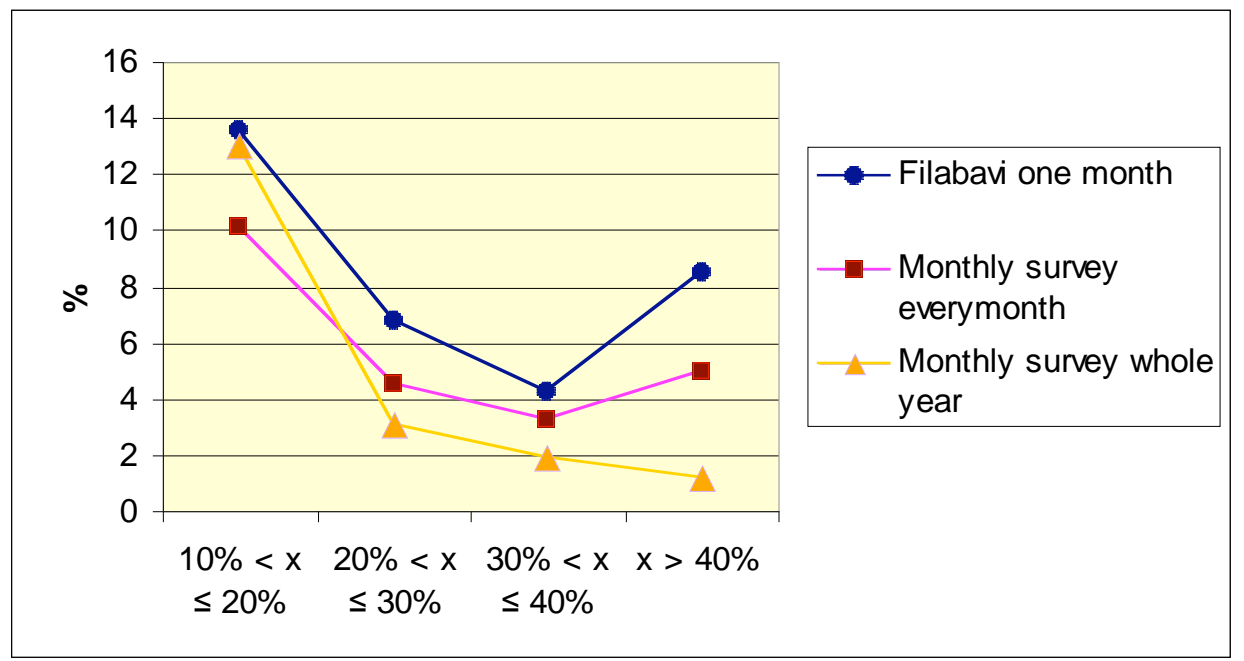

Fig. (2). The share of households with a ratio (x) of health expenditures to capacity to pay from two data sets.

The proportion of households with a ratio $(\mathrm{x})$ of health expenditures to capacity to pay within the different intervals was calculated using data from the FilaBavi re-census in 2001 and from the special survey in 2001/02. Of the total 10,220 households in the FilaBavi survey there were $33 \%$ with a healthcare expenditure of greater than $10 \%$ of the household's capacity to pay, Of the 621 households in the special survey, $23 \%$ and $19 \%$ had healthcare expenditure greater that $10 \%$ of the household's capacity to pay, monthly and during the whole year, respectively. The ratios of households with healthcare expenditures greater than $10 \%$, $20 \%, 30 \%$ and $40 \%$ of their payment capability were approximately $13.5 \% ; 7 \% ; 4 \%$ and $8.5 \%$ respectively in the Filabavi survey, and $10.1 \%, 4.5 \%, 3.3 \%, 5 \%$ (monthly) and $13 \%, 3 \%, 1.9 \%$ and $1.1 \%$ (whole year) respectively in the special survey.

\section{DISCUSSIONS}

In this study, we described the statistics of the level of catastrophic healthcare spending as a percentage of capacity to pay as the ratios of households with healthcare expenditures greater than $10 \%, 20 \%, 30 \%$, and $40 \%$ of their payment capability for both the FilaBavi survey and the special survey. Then we compared the size of catastrophic health expenditure being estimated from three different data sets in Vietnam. From one data set, the VLSS 1997/98, Xu et al. [2] estimated that over $10 \%$ of Vietnamese households experienced catastrophic health spending. We compared this to data from the FilaBavi demographic surveillance site in northern Vietnam. From FilaBavi we have two sets of data; one from the re-survey in 2001 and one from a special survey during 2001/02.

Our findings from these data is that on average $5 \%$ of the households have had catastrophic health spending in each separate month and $1 \%$ for the whole year. However, when using the cross sectional data set, also from the surveillance site and covering the same year (with a recall period of one month), the share of catastrophic health spending households is nearly $9 \%$.

The main difference between these data sets is that both the VLSS and the FilaBavi re-survey are cross sectional with a recall period of one month. The special survey is based on panel data. The households were followed during a yearlong period and interviewed once every month having the households keeping daily notes of their expenditure. The result is a large difference between the special survey and the other two. Possible explanations for this wide difference in estimates are the following:

(i) When studying only a single month one expects to find a larger share of catastrophic health expenditure than if the study period is an entire year. In the latter case, households have a longer time to balance income versus serious medical events.

(ii) The short study duration, however, is unlikely to be the only explanation for the differences that were observed. If half of the households that during a one-month study experience catastrophic health spending do not have such expenditure during the rest of the year, then (if the share is $10 \%$ within a given month) a majority of households would have had a month with catastrophic spending. We suggest that this is unlikely. A more plausible explanation is the recall period. It is possible that households with large healthcare expenditures over a longer time than the preceding month may tend to include also these preceding expenditures, since their perception is one of a heavy economic burden due to healthcare expenses.

There are, however, limitations in our study that could preclude us from making the above conclusions:

(i) The sample in our survey is small compared to the others, with just 621 households compared to 5,966 and 10,220 in cross sectional studies for one month. However, our survey is longitudinal over a 12 month period, so the total number of interviews is comparable $(621 \times 12=7,450)$. Moreover, health services or drugs were used to treat almost all of the illness episodes $(97 \%$ of total 8,380 episodes).

(ii) The study by $\mathrm{Xu}$ et al. used data covering 1997/98 whereas our survey covers 2001/02. Economic growth and policy reform could explain at least part of the difference observed. However, judging from Table 3 above, the share of households living below the poverty 
lines has not dramatically changed during these years. In addition, there was no substantial change in health financing in Vietnam during this period.

(iii) The Bavi district may not be representative of the whole of rural Vietnam. Against this speaks the fact that this district was chosen to be representative at least of northern rural Vietnam and that the expenditure and poverty patterns displayed in Table $\mathbf{2}$ do not indicate any dramatic differences to the VLSS estimates.

The calculation of household monthly catastrophic expenditure shows that the number of households with threshold excess $40 \%$ of health expenditures to capacity to pay in July 2001, which is $10.3 \%$ of housholds (CI: $8.4 \%$ $12.2 \%)$. This is the first month we collect the data. During this time, households have not been using daily note to keep track of their income, expenditure and their illness. They just provided the data based on their memory. The comparison results for the expenditure in July 2001 in special survey with that from the data of Filabavi (which is of $8.5 \%$ ) and of VLSS (which is $10.45 \%$ ) showed statistically insignificant differences. This would support for strengthen of longitudinal study is that avoided the recall bias as conducting the cross-sectional surveys.

Within this background, it is our conclusion that these limitations do not explain the large difference in the estimates for catastrophic health spending that we have reported above. Our suggestion is that our findings indicate that there is a large risk of overestimating the problem when using cross sectional studies with a short recall period.

It is possible that people could suffer from catastrophic health expenditure in one month, but may not have catastrophic health expenditure for the whole year $(1 \%$ of households have catastrophic health expenditure with a ratio greater than $40 \%$ of health expenditures to capacity to pay for whole year in the our data against $5.0 \%$ (our data); $8.5 \%$ (Filabavi data) and 10.5\% (VLSS data) for one month).

For a comprehensive picture of whether there are catastrophic consequences for a household, it is necessary to interpret the findings in the context of broader economic access. In evaluating the magnitude of out-of-pocket payments for health services and drugs, one must bear in mind that a burden of payment can be due to either low or very high financial barriers to health services. Health service costs may put a regressive cost burden on households, especially in developing country $[25,26]$. Even thought the ratio of health expenses to income for the poor is smaller than that for the rich, the poor still face the high user fees and may restrict their utilization of health services. We observe that due to the lack of economic access, when getting sick, a poor person may ignore the illness and not seek care [27]. Therefore, considering only those costs that arise relative to available household resources does not provide a full picture of economic access [28]. The immediate loss of income due to absence from work and large out-of-pocket expenses to cover the necessary medical care are further important assessments of economic burdens on household due to illness and healthcare utilization that must be considered [29, 30]. Illness also causes large and intangible costs on households in terms of the quality of life, discomfort and pain.
The cost of basic healthcare is critically important in deciding what services to use and when. When sick or confined to hospital due to illness, the poor are unable to work and cannot earn money, because their income is usually derived from physical labor. This compounding problem leads to a lack of savings by the poor. As a result, they may choose to ignore their illness or self-treat. Without proper treatment, their health can continue to deteriorate and may get to the stage where they are incapacitated. As a result of the cost of healthcare and the corresponding loss of income whilst sick, they may fall even deeper into poverty [31].

Our data are likely to underestimate the burden of illness for several reasons. We have only measured the household out-of-pocket expenditures for healthcare, and have not measured the income losses, or time costs due to illness that are incurred by households. These losses are presumably large in comparison to out-of-pocket expenditures, especially for households that face serious illnesses [32]. However, we have limited the scope of this study to out-of-pocket healthcare payments since these are considered to be a relatively large problem in Vietnam compared to many other countries [2, 33].

Such explanations should not be used to lessen the seriousness of the problem, however. In our study, $11 \%$ of the households had healthcare expenditures in excess of $20 \%$ of their capacity to pay and for $5 \%$ these expenditures exceeded $40 \%$ of their capacity to pay. Over time, these percentages will aggregate to a substantial percentage of the population. Catastrophic spending is therefore not a small problem. Even in the special survey the proportion of households that have large health expenditure is substantial (Fig. 2). For $6 \%$ of the households this spending amounts to more than $20 \%$ of total spending and for $3 \%$ it is more than $30 \%$. Also, having over $1 \%$ of households that during one year have health spending in excess of $40 \%$ of total spending for the whole year is a large problem.

We recommend further methodological study into household catastrophic health expenditure. More refined methods and more accurate measurements will help to provide a strong evidence base from which the development of appropriate social policies to reduce the burden of healthcare expenditure, especially among the poor and to decrease the gap between poor and rich can be built.

\section{ACKNOWLEDGEMENTS}

This study was conducted in the Epidemiological Field Laboratory for health systems research in Vietnam (FILABAVI), a collaborative research project between Hanoi Medical University and the Division of International Health (IHCAR), Karolinska Institute in Stockholm and Umeå International School of Public Health, Umeå, Sweden. Funding from Sida/SAREC, Stockholm, is gratefully acknowledged, although the organisation played no direct role in our study.

\section{COMPETING INTERESTS}

None declared. 


\section{REFERENCES}

[1] Su TT, Kouyate B, Flessa S. Catastrophic household expenditure for health care in a lowincome society: a study from Nouna District, Burkina Faso. Bull World Health Organ 2006; 84(1): 21-7.

[2] Xu K, Evans DB, Kadama P, Zeramdini R, Klavus J, Murray CJL. Household catastrophic health expenditure: a multicountry analysis. Lancet 2003; 362(9378): 111.

[3] World Health Organization. The world health report 2000; Health systems: improving performance, Geneva 2000.

[4] Garg CC, Karan AK. Out-Of-Pocket Expenditure and Impoverishment: Policy Implications for Targeted Populations in India Presentation made at Forum 9, Mumbai, India 2005.

[5] Xu K, Evans DB, Kadama PJN, Ogwal P, Nabukhonzo P, Aguilar A. Understanding the impact of eliminating user fees: Utilization and catastrophic health expenditures in Uganda. Soc Sci Med 2006, 62(4): 866 .

[6] Phuong DN. Issues of equity and effectiveness in health care in Vietnam. In: Hung PM, Minas HI, Liu Y, Dahlgren G, Hsio WC. Efficient, Equity-oriented strategies for health international perspectives-focus on Vietnam. CIMH Melbourne, Australia 2000; pp. 15-26.

[7] World Bank. Development Indicators. CD-Rom The World Bank: Washington, DC 2003

[8] Ministry of Health. Health Statistics Yearbook. Hanoi-Vietnam: Ministry of Health 2007.

[9] Ministry of Health. Health Statistics Yearbook. Hanoi Vietnam: Ministry of Health 2003.

[10] The United Nations Country Team in Vietnam. Health Care Financing for Vietnam. Discussion Paper 2003, No. 2.

[11] Ministry of Health. Vietnam Health Report 2002 Medical Publishing House: Hanoi Vietnam 2002.

[12] Hung PM, Dung TV, Dahlgren G. Efficient equity-oriented health sector reform: A Vietnamese perspective on some key issues. In: Hung PM, Minas IH, Liu Y, Eds. Efficient, Equity-oriented strategies for health international perspectives-focus on Vietnam 2000.

[13] World Bank, Sida, AusAID, and the Royal Netherlands Embassy in co-operation with the Ministry of Health V. Vietnam - Growing Healthy: A Review of Vietnam's health sector. Ministry of Health, Vietnam 2001, Report No. 22210-VN.

[14] General Statistical Office. Statistical Handbook Hanoi Vietnam: Statistical Publishing House 1999.

[15] Chuc NTK, Diwanm VK. FILABAVI, a demographic surveillance site, an epidemiological field laboratory in Vietnam. Scand Pub Health 2003, 31(62): 3-7.

[16] Berki SE. A look at catastrophic medical expenses and the poor. Health Aff (Millwood) 1986; 5(4): 138-45.

[17] Prescott N, Pradhan M. Coping with Catastrophic Health Shocks. Organized by the Poverty and Inequality Advisory Unit of the Sustainable Development Department: Washington, DC 1999.

[18] Xu K. Distribution of health payments and catastrophic expenditures methodology World Health Organization: Department "Health System Financing" (HSF) Cluster "Evidence and Information for Policy" (EIP) Geneva 2005; p. 2.
[19] Xu K, Klavus J, Kawabata K. Household health system contributions and capacity to pay: Definitional, empirical and technical challenges. In: Murray CJL, Evans DB, Eds. Health systems performance assessment 2003 Debates, Methods and Empiricism WHO, Geneva 2003.

[20] Xu K, Klavus J, Kawabata K. Household health system contributions and capacity to pay: Definitional, empirical and technical challenges. In: Murray CJL, Evans DB, Eds. Health systems performance assessment 2003 Debates, Methods and Empiricism WHO, Geneva 2003.

[21] World Bank. An International Assessment of Health care Financing. In: Dunlop DM, Martins JM, Eds. Lesson for Developing Countries. Economic Development Institute: The World Bank 1995.

[22] Hanoi Medical University, Health Strategy and Policy Institute, and Karolinska Institute. FILABAVI, an Epidemiological Field Laboratory- a demographic surveillance site for the study of the health sector reform in Vietnam. Book Published in Medical publishing house: Hanoi, Vietnam 2002.

[23] World Health Organization. Health Financing: A basis guide. WHO Library Cataloguing in Publication Data 2006; ISBN 929061143 x (NLM Classification: W 74).

[24] World Bank. Vietnam development report 2000. Attacking Poverty: Washington, DC 1999.

[25] Fabbricant SJ, Kamara CW, Mills A. Why the poor pay more: Household curative expenditures in rural Sierra Leone. Int J Health Plann Manage 1999; 14: 179-99.

[26] World Bank. Vietnam Growing Healthy: A Review of Vietnam's Health Sector. Washington, DC: World Bank 2001, Report No. 22210-VN.

[27] Wagstaff A, Doorslaer. Catastrophe and impoverishment in paying for health care: with applications to Vietnam 1993-1998. Health Econ 2003; 12: 921-34.

[28] McIntyrea D, Thiedea M, Dahlgrenb G, Whiteheadb M. What are the economic consequences for households of illness and of paying for health care in low- and middle-income country contexts? Soc Sci Med 2006; 62: 858-65.

[29] Gilson L. Government health care charges: is equity being abandoned? Evaluation and planning Centre for Health, London School of Hygiene and Tropical Medicine 1988; No. 15.

[30] Russell S. The economic burden of illness for household in developing countries: A review of studies focusing on malaria, tuberculosis, and human immunodeficiency virus/acquired immunodeficiency syndrome. Am J Trop Med Hyg, Copyright by the Am Soc Trop Med Hyg 2004; 71(Suppl 2): pp.147-55

[31] Hjortberg C, Hcuiadc-Tco Z. Health care utilisation in a developing country- the case of Zambia. (Doctoral thesis) Lund University KFS $\mathrm{AB}$, Lund 2004.

[32] Sauerborn R, Ibrango I, Nougtara A, et al. The economic costs of illness for rural households in Burkina Faso Diesfeld HJ. Trop Med Parasitol 1995; 46(1): 54-60.

[33] Khe ND, Toan NV, Xuan LTT, Eriksson B, Hojer B, Diwan VK. Primary health concept revisited: Where do people seek health care in a rural area of Vietnam? Health Policy 2002; 61(1): 95.

(C) Thuan et al.; Licensee Bentham Open.

This is an open access article licensed under the terms of the Creative Commons Attribution Non-Commercial License (http://creativecommons.org/licenses/by$\mathrm{nc} / 3.0 /)$, which permits unrestricted, non-commercial use, distribution and reproduction in any medium, provided the work is properly cited 